\title{
ВОЗДЕЙСТВИЕ ЭЛЕКТРОННЫХ СМИ НА СОЦИОКУЛЬТУРНОЕ ПРОСТРАНСТВО РЕГИОНА
}

\section{EFFECT OF ELECTRONIC MEDIA ON THE SOCIO-CULTURAL SPACE OF THE REGION \\ E. Derevtzova}

Summary: The article discusses the features of the influence of electronic media on the socio-cultural space of the region. In the information society, electronic mass media, freed from circulation and distributors, were able to virtually unite an infinite number of readers and subscribers, as well as technically unlimited impact on the processes in the socio-cultural space. Against this background, in the Kemerovo region, as in Russia as a whole, the development of mechanisms that ensure the socio-cultural representation and maintenance of the system of norms and values does not follow regional, but rather global trends. The general desire of mass culture to integrate into the mainstream - the western cultural space, is less and less leading to conflicts with tradition, mentality, lifestyle and spiritual attitudes, which are already mainly adjusted to global cultural influences.

Keywords: mass media, socio-cultural environment, socio-cultural space.

\author{
Деревцова Елена Анатольевна \\ Преподаватель, соискатель, ФГБОУ ВО «Кемеровский \\ государственный институт культуры» \\ derevtzova@mail.ru
}

Аннотация: В статье рассматриваются особенности влияния электронных СМИ на социокультурное пространство региона. В информационном обществе электронные СМИ, освободившись от тиражей и распространителей, получили возможность виртуального объединения бесконечного числа читателей и подписчиков, а также технически неограниченного воздействия на процессы, идущие в социокультурном пространстве. На этом фоне в Кемеровской области, как и в России в целом, развитие механизмов, обеспечивающих социально-культурную репрезентацию и поддержание системы норм и ценностей, идет в русле не региональных, а скорее - глобальных тенденций. Общее стремление массовой культуры интегрироваться в мэйнстрим западное культурное пространство, все реже ведет к коллизиям с традицией, ментальностью, образом жизни и духовными установками, которые уже в основном скорректированы к глобальным культурным влияниям.

Ключевые слова: средства массовой информации, социокультурная среда, социокультурное пространство.

числе и под воздействием электронных СМИ, схожие чувства, интересы, запросы и побуждения.

Социокультурное пространство не ограничивается физическим, т.е. реальным пространством, так как это, прежде всего, пространственная среда конструируемая самим человеком, это физическое и ментальное выражение организации им своего и коллективного пространства, так как человек и его социальные связи формируют социокультурное пространство как специфическую пространственно-временную целостность[2, с.150].

Таким образом, социокультурное пространство выходит за пределы физических (географических) границ, так как представляет собой «конструируемую человеком пространственную среду», специфическое «физическое и ментальное выражение организации пространства человеком», без которого оно не существует. Именно человек и его социальные взаимодействия формируют социокультурное пространство в виде пространственно-временной целостности.

В рамках коммуникативной (включая и виртуальную составляющую) среды человек формирует социокультурное пространство места, города, региона, жители которых становятся носителями социальной и культурной жизни, на которую накладывает отпечаток этническая и 
традиционно конфессиональная принадлежность, уровень образования, профессиональные занятия. В этом смысле Е.В. Орлова выводит смысловое наполнение анализируемого понятия из совокупности социальных и культурных особенностей, взаимодействующих на определенной территории[2, с.151].

Полагаем, более корректным вести речь не об особенностях (не отрицая их наличия), а о ценностях, среди которых доминирует традиционная система, в рамках которой наивысшей ценностью обладают жизнь, семья и порядок[3, с.96]. Кним в последние годы добавились признание самоценности независимости и свободы. Карьера не оказалась приоритетной жизненной ценностью. В этом смысле ценностный аспект имеет существенное значение и особенно значим с позиции социокультурного развития, как индивида, так и регионального сообщества и формирования их мировоззрения[4, с.5].

Социокультурное пространство региона формируется в коммуникативной среде, в которой значительную роль играют СМИ. При этом специфика и характер коммуникативных процессов определяют отличительные черты социокультуры региона.

Примечательно, как на одном из «круглых столов», прошедших в рамках конференции по социокультурной эволюции регионов России, участники, констатируя «недостаточность реализации социокультурного потенциала» российских регионов, вели речь о мировом кризисе, модернизации, образовании, демографии, семейном поведении, миграции, здравоохранении, инновациях, динамике гражданской активности в контексте социального самочувствия населения, проблемах управления регионами и даже о лесных пожара[5, с. 140]. Таким образом, заявленная проблематика была расширена до степени утраты тематических рамок дискуссии, а значит и понимания дефиниции сочиокультурное пространство, которая помогает представить общество в единстве социальных и культурных аспектов.

Культура в данном случае является системой норм, ценностей и культурных феноменов, обеспечивающих единство действий социальных групп, объединяя общество. Единицами культурологического исследования здесь становятся сложившиеся типы социального взаимодействия, механизмы их репродукции[6].

Население российских регионов обладает значительным социальным, культурным и иным потенциалом, который слабо преобразуется в активно работающий капитал. Его ограниченное использование признается главной причиной сдерживания перехода к информационной, инновационной экономике и, соответственно, медленного роста качества жизни[5, с.141].

В то же время, насколько решение поставленных про- блем зависит от состояния (развития) социокультурного пространства и его динамики? Из экономико-правовых исследований известно как институциональная среда воздействует на динамику перехода к инновационному обществу, что же касается влияния социокультурной динамики, то такое влияние остается неопределенным. В то же время, как институциональная, так и социокультурная среда формируются людьми, гражданами, властью, но при более активном участии СМИ.

Применительно к проблематике и контексту настоящей статьи смысловое наполнение социокультурного пространства прямо производно от исторических, природно-климатических, социально-экономических, религиозных и культурно-национальных особенностей, реализующихся в регионе. Исходя из этого, философско-культурологический анализ сочиокультурного пространства, выявление его базовых и переменных системных характеристик следует основывать на локальных проявлениях, но в контексте национального и глобального культурного развития. В то же время, таких локальных проявлений остается все меньше.

\section{Сочиокультурное пространство и региональные СМИ}

С началом цифровой (информационной) глобализации региональные сообщества, порвав с традиционным «провинциализмом», стали демонстрировать относительно высокий и однонаправленный динамизм социокультурных изменений, производных от социальноэкономической динамики, трансформации структуры потребностей, интересов, ценностей (по социальным группам), способов (реальных и виртуальных) социального взаимодействия. При этом поиск новых социокультурных образцов идет через переоценку «старых», или их «отмиранием» и появлением новых. Нарастающая изменчивость становится главным признаком современной социокультурной динамики в любом российском регионе.

Ход и направление изменений определяются влиянием внешних и внутренних факторов, главным из которых в информационном обществе становится (и признается) массовая информация, а главным социальным агентом становятся средства ее собирающие, обрабатывающие, продуцирующие и транслирующие, т.е. электронные СМИ. С их помощью передается не только и не просто информация (которая сегодня в «чистом» виде уже практически не существует), а оценки, суждения, эмоции, модели поведения и т.п. формирующие или трансформирующие картины мира и идентичности[7, с.9]. Таким образом, СМИ, с одной стороны, связывая воедино разрозненные культуры регионов России, демонстрируют и их различия. При этом общее стремление современной массовой культуры интегрироваться в мэйнстрим - западное культурное пространство - ве- 
дет к частым коллизиям с традицией, ментальностью, образом жизни и духовными установками, которые существенно корректируют способы и сроки адаптации к глобальным культурным влияниям.

Информационное пространство Кемеровской области насыщено электронными СМИ, которые можно условно поделить на группы. К информационным отнесем следующие сайты и порталы: Новости Кемеровской области (novostikuzbassa.ru), Тайга.info (tayga.info), Новости на a42.ru (news.a42.ru), Родной Новокузнецк (kuznya. info); gis42 - Городской Информационный Сайт (www. gis42.ru), «Кузбасс Сегодня» (kuzbass-today.ru), Бюро Экспресс-Новостей (express-news.ru), Информационно-новостной и деловой сайт Кузбасса (www.mediakuzbass. ru), Кемеровское отделение Сибирского Агентства Новостей (kem.sibnovosti.ru), Сейчас в Кузбассе, информационный портал Кемеровской области (zhkhlight.ru) и др. Значительную долю медиарынка и медиапространства занимают деловые сайты: Бизнес-портал Кузбасса (www. avant-partner.ru), Журнал Капитал (biz.a42.ru), Сибирский Деловой Портал (www.sibdepo.ru), Кемеровская интернет-газета (кемерово-объявления.рф), Недвижимость. Регион 42 - журнал (www.nr42.ru), Стройка Кузбасс (1stroykuzbass.ru) и др. Активно работают специализированные молодежные, женские, профессиональные и хобби сайты: В кругу семьи (goodparents.ucoz.ru), Женский журнал «Клуб-Кемеровчанка.ru» (club-kemerovchanka. ru), Женский журнал Птица (bird.a42.ru), Кемеровский студенческий портал КГМОО «Студмедиа» (studmedia. info), Молодёжный блог о Кемерово (ilovekem.ru) и др. Свои сайты имеют традиционные печатные издания: «Комсомольская правда» (www.kem.kp.ru) и др.

Все электронные СМИ, независимо от формы собственности, формально функционируют свободно, конкурируя друг с другом. Государство, в лице органов власти Кемеровской области, действуя в рамках Закона РФ «О СМИ», формально не вмешивается в редакционную политику частных и корпоративных СМИ, за исключением контроля за детским и подростковым контентом[8].

\section{Черты влияния СМИ на реализацию сочиокультурных станАартов и норм}

В России исторически сложилась ведущая роль государства (официальной идеологии и пропаганды) в формировании социокультурного пространства, ценностей и норм[9, с.181]. В этой связи нельзя не учитывать, что система политического управления, которая сформировавшаяся в Кемеровской области с конца 1990-х годов, имела так называемую социально - авторитарную направленность[10]. В рейтинге региональной демократии Кемеровская область не поднималась выше 71-72 места[11]. Нарастание авторитарных тенденций не было региональной особенностью, а отражало общую ситуацию в российской политике, где в сравнении с 1990 го- дами были радикально сужены практики электоральной демократии[12, с.363], при минимальном участии гражданского общества в социально-политических процесса[13, с.92]. В этой связи региональные СМИ отражали, прежде всего, официальную позицию региональной исполнительной власти, формируя (или пытаясь формировать) лояльность населения к проводимой политике. Именно этот подход формировал структуру и наполнение социокультурных стандартов. Здесь проявились две основные черты влияния СМИ на реализацию социокультурных стандартов и норм: первая - директивность административность и вторая - официозность.

Современные исследования показывают отсутствие корреляции между демократией в регионе и уровнем развития его экономики, равно как и уровнем жизни. В этом смысле их рост автоматически не обеспечивает демократии. Современные исследования показывают, что эти три сферы в России «в высокой степени автономны, существуют в параллельных мирах и пересекаются очень слабо»[11].

На этом фоне развитие механизмов, обеспечивающих социально-культурную репрезентацию и поддержание системы норм и ценностей, идет в русле не региональных, а скорее - глобальных тенденций. Так, с 2020 г. в Кемеровской области начата фактическая реализация регионального круглосуточного телевизионного цифрового канала в разрешении HD. Вещание приобрело современный формат (совокупность содержательных, адресных, стилистических и технологических элементов, обслуживающих концепцию вещательного канала[14, с.30]) не только технически. В данном случае проявился глобализм, как общая черта влияния СМИ на социокультурные ценности и нормы.

Планируется, что в сетке вещания нового кемеровского областного круглосуточного канала «Кузбасс - 1» будут преобладать «самые интересные фильмы, рейтинговые сериалы, концерты популярных звёзд и спортивные матчи», а из местных материалов планируются новостные программы, а также «рецепты кузбасской кухни и знаковые места региона». Таким образом, ориентация на формирование специфических региональных социокультурных стандартов, пока не просматривается. Судя по плану вещания, преобладание стандартного современного контента преследует цель привлечения аудитории и, соответственно, рекламодателе[15, с.14]. В этой связи нетрудно прогнозировать на новом региональном канале высокую насыщенность рекламой.

В то же время, формат канала пока не вполне ясен. Предполагается реализовать на базе «Кузбасс $1 \mathrm{HD}$ » интерактивные инструменты взаимодействия с аудиторией, которая будет участвовать в формировании контента, предоставляя «актуальную информацию», однако, концепции такого взаимодействия пока не представлено. 
Будучи традиционными каналами (и формами) выражения общественного мнения, СМИ остаются и средствами массовой коммуникации. В то же время, российское общество, а соответственно и «россияне», «с трудом осваиваются с феноменами массового влияния, которые подобны западным «рекламно-рыночным» или «рекламнополитическим» образцам». Речь в данном случае идет об «извечной проблеме общественного человека»: как и в какой степени он может поддаваться влиянию (а нередко - и давлению) коммуникативных средств «массового поражения[16, с. 24]».

Современная теория массовых коммуникаций последние десятилетия исходит из опосредованности СМИ наших знаний о реальности, которая преподается (или «препарируется») в определенной медиальной интерпретации. Таким образом, реальность приобретает статус общественного события лишь через медиальное отображение[17, с. 59].

Для понимания влияния электронных СМИ на формирование социокультурных стандартов важна структура потребляемого населением цифрового контента. По данным исследования структуры такого потребления среди зрителей ТВ МТС[18] в 2019 г. абсолютно доминировали фильмы и сериалы, которые заняли до 45\% общего просмотрового времени. Вторую позицию занял детский контент - 24\%, третье - с $11 \%$ заняли развлекательные программы.

Зрители спутникового ТВ предпочитают новости и программы о бизнесе (36\% трафика). На втором месте также оказались каналы для детей (21\%) и документалистика (15\%). В этом сегменте фильмы и сериалы заняли лишь четвертое место с 10\% просмотрового времени, далее разместились: познавательные - 8\% и спортивные передачи - 3\%. Аудитория цифрового интерактивного телевидения в 2019 г. смотрела в основном спорт (20\%) и познавательные программы (18\%).

Очевидные различия связаны со структурой доступа к информации. Для тех, кто смотрит спутниковые передачи, телевидение остается основным источником информации, тогда как кабельное и цифровое интерактивное ТВ, предполагая интернет, эту функцию уже не выполняют, обеспечивая, в основном, развлекательный контент. Также опрос показал, что кабельное и спутниковое телевидение в Кузбассе принято смотреть семьей, тогда как цифровое интерактивное телевидение - более индивидуализировано.

Исследование показало рост в 2019 г. в совокупном объеме вещания доли местных и региональных каналов, которые в прежние годы имели не более 0,7\% просмотрового времени. В 2019 г. их доля превысила 4,1\%. В то же время, эксперты склонны объяснять это не столько ростом качества контента, сколько технологическими причинами, а именно - отключением аналогового сигнала. В то же время это свидетельствует и о присутствии (о качественном росте вести речь преждевременно) черт регионализма.

В среднем, по данным трафика МТС среднестатистический зритель в 2019 г. тратил на просмотр телевидения 3 часа 51 минуту в день (+ 11 мин. к 2018 г.). При этом prime-time приходилось в будни - на 16:00 - 20:00, тогда как в выходные и праздники время равномерно распределялось в течение дня и вечера[19].

Цифровые и кабельные операторы, охватывая практически все население области, ведут свою деятельность в регионе в соответствии с условиями, которые созданы господствующими элитами и воспринимаются ими как объективные условия для реализации собственных коммерческих интересов. Задачи формирования социокультурных стандартов, как таковой, не существует, что вполне понятно в рамках либерально-буржуазной идеологии. В то же время, независимо от того, понимают ли они этот факт или нет, эти операторы так или иначе воздействуют на этот процесс своим контентом, формирующимся в основном исходя из задач максимального охвата населения рекламой. Такой подход не может не деформировать традиционно сложившиеся и «работающие» социокультурные нормы, подчиняя их не общественным, а иным интересам и целям.

Таким образом, в деятельности современных СМИ, оказывающих существенное влияние на социокультурное пространство региона, проявляется несколько основных черт.

1. Директивность и административность.

2. Официозность официальных и близких к ним СМИ.

3. Медиапространство Кузбасса неотъемлемая составная часть глобального медиапространства, поэтому в политике региональных СМИ не может не проявляться глобализм.

4. Работая в регионе, СМИ не могут не учитывать его особенности, историю, культуру, традиции, что отражается в регионализме.

5. Агрессивная реклама подавляет тот необходимый контент, который выражает культурно-исторические тендеции в регионе.

6. Абсолютное преобладание в сетке вещания развлекательного, спортивного и детского контента.

В заключении подчеркнем, что указанные черты есть результат особенностей вещания ТВ, радио и т.д., которые формируют типовую (усредненную) для России социокультурную среду общества потребления, в которой все сложнее улавливаются региональные особенности, и которая выражает культурно-исторические тенденции в регионе. 


\section{ЛИТЕРАТУРА}

1. Закон РФ от 27.12.1991 №2124-1 (ред. от 02.12.2019) «0 средствах массовой информации»// ВСНД и ВС РФ. 1992. №7. Ст. 300.

2. Орлова Е.В. Социокультурное пространство: к определению понятия// Манускрипт. 2017. №7 (81). С. 149-152.

3. Шабунова А.А., Гулин К.А., Ласточкина М.А. и др. Модернизация экономики региона: социокультурные аспекты. - Вологда: ИСЭРТ РАН, 2012. - 158 с.

4. Ласточкина М.А. Ценности населения в социокультурном пространстве региона//Universum: экономика и юриспруденция. 2015. №8 (19). С. 5.

5. Дергунова Н.В., Волков А.В., Светуньков М.Г. Социокультурная динамика регионов в условиях финансово-экономического кризиса// Социологические исследования. 2011. №7 (327). С. 140-141.

6. Ищенко Н.С. Социокультурное пространство как статическая характеристика социокультуры// http://fki.lgaki.info/2017/11/20/

7. Гуляев С.Б. Влияние СМИ на социокультурную динамику в современном российском обществе: дисс. ...канд. социол. наук. 22.00.06. М., 2009. С. 9.

8. $0 б$ утверждении региональной программы «Обеспечение информационной безопасности детей, проиводства информационной продукции для детей и оборота информационной продукции в Кузбасее» на 2019-2020 годы. Распоряжение Правительства Кемеровской области № 662 от 29 октября 2019 г.// Электронный бюллетень Правительства кемеровской области - Кузбасса http://www.zakon.kemobl.ru/bulletin/253767

9. Григорьева Е.Б. Современный взгляд на исследование авторитарности в России// Вестник Томского государственного университета. Философия. Социология. Политология. 2012. № 3(19). С. 177-191.

10. Демократический аудит регионов. Проект Института «Общественная экспертиза», фонда «ИНДЕМ» и Аналитического центра «Меркатор» http://www. freepress.ru/publish043.shtml

11. Социальный атлас российских регионов. URL: http://www.socpol.ru (дата обращения: 26.05.2019)

12. Клименков М.А. Научно-экспертное сообщество и власть : опыт взаимодействия в регионе (на примере Кемеровской области)// Известия Саратовского университета. Новая серия. Серия Социология. Политология. 2019. Вып. 19 №3. С. 360-365.

13. Никовская Л.И., Якимец В.Н. Политика региональных властей в России: типы, субъекты, институты и современные вызовы // Полис. 2011. № 1. С. 80-96.

14. Мясникова М.А. Форматы и жанры как категории телевизионной морфологии// Вестник Новосибирского государственного университета. Серия : История. Филология. 2011. Вып. 10. №6. С. 29-35.

15. Бойченко И.В. Необходимость управления качеством услуг телевизионного контента с целью повышения степени удовлетворенности телезрителей// T-Comm: Телекоммуникации и транспорт. 2011. Т. 5 № 12. С. 14-15

16. Ивченков С.Г. Механизм воздействия СМИ на общественное мнение в регионе// Известия Саратовского университета. Новая серия. Серия Социология. Политология. 2008. Вып. 8. №2. С. 21-25.

17. Больц Н. Азбука медиа. пер. с нем. Л.Ионина и А.Черных. М.: Европа, 2011. 132 с.

18. Шарков Ф.И., Бузин В.Н. Интегрированные коммуникации. Массовые коммуникации и медиа планирование. Учебник / под общ. ред.Ф.И. Шаркова. М., С. 39-40.

19. Что смотрели кузбассовцы по телевизору в прошлом году// портал VSE42.ru. 2020. 29 января, http://vse42.ru/news/31073616

(с Деревцова Елена Анатольевна (derevtzova@mail.ru). 